\title{
A naturalização das queixas escolares em periódicos científicos: contribuições da Psicologia Histórico-Cultural
}

\author{
Nilza Sanches Tessaro Leonardo \\ Universidade Estadual de Maringá - PR \\ Záira Fátima de Rezende Gonzalez Leal \\ Universidade Estadual de Maringá - PR \\ Solange Pereira Marques Rossato \\ UNESP/Assis - SP
}

\section{Resumo}

Para o desenvolvimento deste estudo realizou-se, por meio de indexadores nacionais e internacionais, uma busca em periódicos científicos por artigos que tratassem da queixa/fracasso escolar (dificuldade de aprendizagem). Com o estudo objetivamos verificar as perspectivas teóricas e as concepções de queixa/fracasso escolar presentes nesses artigos. Os 77 artigos encontrados foram estruturados a partir de categorias e analisados do ponto de vista da Psicologia Histórico-Cultural. Os resultados revelaram que as concepções que embasam as reflexões sobre a queixa/fracasso escolar são centradas no indivíduo (67\%), voltadas à questão institucional (9\%), relacionadas à formação profissional (5\%) e não centradas no indivíduo (19\%). Quanto à perspectiva teórica, destaca-se uma perspectiva não crítica (65\%). Enfatizamos que as produções científicas devem contribuir para desvelar a crença de que as crianças e adolescentes com dificuldades de aprendizagem são naturalmente fracassadas, e que é preciso refletir por que tantos estudos ainda têm como foco o insucesso escolar.

Palavras-chave: Fracasso escolar; dificuldades de aprendizagem; Psicologia Histórico-Cultural.

\section{The naturalization of school problems in scientific journals: contributions from Historic-Cultural Psychology}

\begin{abstract}
For the development of this study we carried through, a research on scientific papers, through national and international indexers. We selected articles that dealt with the school complaint/failure (learning difficulty). With the study we aim at verifying the theoretical perspectives and the conceptions of school complaint/failure in the current articles. The 77 articles selected have been structuralized by means of categories and analyzed from point of view of Historical-Cultural Psychology. The results had revealed that the conceptions that point the reflections on the school complaint/failure are centered on the individual (67\%), aiming the institutional question (9\%), related to the professional formation (5\%), and not centered on the individual (19\%). Regarding the theoretical perspective, there is the prominence of the non-critical one (65\%). We emphasize that the scientific works must contribute to clarify the belief that the children and adolescents with learning difficulties are naturally unsuccessful. Besides, we argue that it is necessary to interrogate why so many studies (papers) still have as focus on school failure.
\end{abstract}

Keywords: Academic failure; Learning difficulties; Historical-Cultural Psychology.

\section{La naturalización de las quejas escolares en periódicos científicos: contribuciones de la Psicología Histórico-Cultural}

\section{Resumen}

Para el desarrollo de este estudio se realizó, por medio de indexadores nacionales e internacionales, una búsqueda en periódicos científicos por artículos que tratasen de la queja/fracaso escolar (dificultad de aprendizaje). Con este estudio se tuvo por objetivo comprobar las perspectivas teóricas y las concepciones de queja/fracaso escolar presentes en esos artículos. Los 77 artículos encontrados fueron estructurados a partir de categorías y analizados del punto de vista de la Psicología Histórico-Cultural. Los resultados enseñaron que las concepciones que fundamentan las reflexiones sobre la queja/fracaso escolar son centradas en el individuo (el 67\%), volcadas a la cuestión institucional (el $9 \%$ ), relacionadas a la formación profesional (el 5\%) y no centradas en el individuo (el 19\%). Cuanto a la perspectiva teórica, se destaca una perspectiva no crítica (el $65 \%)$. Enfatizamos que las producciones científicas deben contribuir para desvelar la creencia de que los niños y adolescentes con dificultades de aprendizaje son naturalmente fracasados, y que es necesario reflexionar por qué tantos estudios aún tienen como foco el fracaso escolar.

Palabras-clave: fracaso escolar; dificultades de aprendizaje; Psicología Histórico-Cultural. 


\section{Introdução}

Atualmente temos no Brasil um grande contingente de crianças frequentando a escola: no ano de 2013, de acordo com o censo escolar, houve 50.04 milhões de matrículas de crianças de 6 a 14 anos na Educação Básica, em escolas estaduais e municipais (MEC, 2013); no entanto, a efetivação da aprendizagem pode representar, para muitos, uma possibilidade distante. O aumento do número de matrículas e o fato de "quase todas" (98,2\% matriculados em 2011, ainda que cerca de 500 mil ainda não frequentem a escola) as crianças de 6 a 14 anos estarem nas escolas não garantem a aprendizagem e o desenvolvimento e não significam oportunidades iguais de escolarização para todos (Brasil, 2013).

Tal afirmativa pode ser mais bem compreendida ao se verificar que, no Brasil, 539.702 crianças e adolescentes de 6 a 14 anos estão fora da escola e que menos de $70 \%$ dos jovens de 16 anos, na média do País, concluem o Ensino Fundamental. Chama a atenção também a estimativa de que apenas $56,1 \%$ das crianças das escolas públicas que concluíram o $3^{\circ}$ ano do Ensino Fundamental obtêm os conhecimentos esperados para essa etapa, como mostra o índice de leitura da Avaliação Brasileira do Ciclo de Alfabetização-Prova ABC (Anuário Brasileiro da Educação Básica, 2013).

Mesmo diante da instauração de reformas educacionais e pactos internacionais, quando se trata de avaliar o indicativo de qualidade (considerado como a taxa de sobrevivência na $5^{\mathrm{a}}$ série), entre os 129 países avaliados, o Brasil ocupava, em 2010, a $88^{a}$ posição. Ainda segundo o Relatório de Monitoramento de Educação para Todos de 2010, da Organização das Nações Unidas para a Educação, Ciência e Cultura (UNESCO, 2010), em nosso país, cerca de 13,8\% dos estudantes abandonam os estudos já no primeiro ano do Ensino Básico. Neste quesito, o País só fica à frente da Nicarágua (26,2\%) na América Latina e, mais uma vez, bem acima da média mundial (2,2\%). Na região da América Latina e Caribe, a taxa de repetência média para todas as séries do Ensino Fundamental é de 4,4\%. No Brasil, o índice é de $18,7 \%$, o maior de todos os países da região ${ }^{1}$. Na avaliação da Unesco, nosso país poderia se encontrar em uma situação melhor se não fosse a baixa qualidade do ensino oferecido.

Estes e outros dados evidenciam a realidade do ensino brasileiro, em que as práticas e políticas educacionais não conseguem atingir todas as crianças em idade escolar, seja quanto à permanência na escola, seja quanto ao sucesso escolar. Esses índices de evasão e repetência configuram uma situação de exclusão e seletividade que marca o processo de escolarização em nosso país. Embora se observe uma tendência à democratização do acesso à escola com o aumento no número de vagas, persistem as dificuldades em

\footnotetext{
1 Na obra de: Viégas, Lygia de Sousa, \& Angelucci, Carla Biancha (Orgs). Políticas públicas em educação \& psicologia escolar. São Paulo: Casa do Psicólogo, 2006, há uma importante discussão que traz a necessidade da crítica ao direcionamento ético-político presente na realização dos ideais de reprovação e não reprovação escolar, que constituem parte da história das demandas mais progressistas, as quais não implicam diretamente no enfrentamento dos problemas escolares e sim numa tentativa de contorná-los.
}

relação à permanência na escola e à qualidade e aprendizagem dos conteúdos científicos.

Conforme os dados do IDEB $^{2}$ sobre o desempenho dos alunos no SAEB e na Prova Brasil em 2011, incluindo-se todas as escolas brasileiras (públicas e privadas), a média (escala de zero a dez) para as séries iniciais do Ensino Fundamental foi 5,0, para as últimas séries do Ensino Fundamental foi 4,1 e no Ensino Médio, 3,7. Esses dados, embora mostrem crescimento, ainda revelam um ensino deficitário e de baixa qualidade, com números muito inferiores aos dos países desenvolvidos, que apresentam a média 6,0.

Os dados oficiais e a realidade encontrada nas salas de aula revelam que muitas crianças estão sujeitas a um processo histórico de marginalização, o que expõe as mazelas educacionais presentes em nosso país que dão vazão às queixas escolares e às dificuldades identificadas pelos educadores no que se refere ao rendimento escolar ou ao comportamento dos alunos, fatores que interferem no processo ensino-aprendizagem e consolidam o fracasso escolar. Tais dificuldades geralmente resultam no encaminhamento destes alunos a atendimento pedagógico, psicológico, médico e outros que possam sanar tal problemática e/ou intervir no diagnóstico/prognóstico de fracasso escolar.

Para Patto, a escola “(...) ensina segundo modelos adequados à aprendizagem de um aluno ideal” (1990, p.340) e, quando se depara com alunos que não aprendem segundo esses modelos, atribui os problemas de aprendizagem a disfunções psiconeurológicas. "Grande parte da produção científica atual acerca dos problemas de escolarização tem centrado suas análises, unicamente, nas características individuais - tomadas como naturalmente patológicas" (Eidt, \& Tuleski, 2007, p.538). Essa leitura desconsidera as condições sociais e econômicas de uma determinada organização social e de um determinado período histórico para a ocorrência do fenômeno, reduzindo-o ao indivíduo e deixando de lado as relações complexas que o envolvem.

Neste sentido, Machado (1997) explica que são produzidas práticas e crenças que constroem justificativas individualizadas no corpo das crianças para explicar a não aprendizagem escolar. As concepções geradas nessas produções entendem as diferenças sociais e o fracasso escolar como fruto da incapacidade individual, naturalizando o meio social; porém é preciso considerar que o sucesso ou o fracasso não respondem apenas a determinações de ordem individual, mas que as várias práticas sociais e do cotidiano escolar são fatores que contribuem para o fracasso escolar, perpetuando o preconceito, a atitude julgadora e os ideais de produtividade. As possibilidades da criança são sempre engendradas em uma rede de relações presentes no contexto social.

Para Facci (2007), culpar pela não aprendizagem escolar um dos envolvidos no processo de ensino, como o aluno, sua família ou o professor escolar resulta em uma explicação simplista e ideológica em que estão imbricados os pressu-

2 Índice de Desenvolvimento da Educação Básica (IDEB) foi criado pelo INEP (Instituto Nacional de Estudos e Pesquisas Educacionais Anísio Teixeira), em 2007, como parte do Plano de Desenvolvimento da Educação (PDE). http://ideb.inep.gov.br/Site/ 
postos neoliberais, que retiram os fatores sociais envolvidos no contexto de produção do fracasso escolar, naturalizando essas questões, pois as localizam no próprio indivíduo.

Diante deste contexto, é fundamental questionarmos o ensino instituído e as mazelas por ele produzidas dentro de um contexto histórico-cultural de determinações e contradições, favorecendo o rompimento com as ideologias que camuflam e ocultam a realidade no que tange às suas contradições. É preciso compreender a produção do fracasso escolar e com ela relacionar-se para além de suas naturalizações e cristalizações, tendo em vista possíveis movimentações de olhares e práticas, a fim de contribuir para que de fato os indivíduos possam, em seu coletivo, apropriar-se da cultura e fazer do conhecimento um instrumento de transformação da realidade de exclusão e desigualdade social (Rossato, 2010).

Por outro lado, embora a educação escolar tenha se universalizado e generalizado, tornando-se possível garantir o acesso de quase todos à educação, ainda são muitos os problemas nesta área, dos quais o principal é o fato de que o conhecimento veiculado pela escola não tem se constituído em instrumento para a formação de uma consciência humanizada, servindo à manutenção do status quo e à reprodução do sistema (Leal, 2010).

Neste contexto, sendo a educação parte integrante e fundamental ao desenvolvimento do indivíduo, faz-se mister um trabalho educativo voltado às formas de produzir esse desenvolvimento de maneira plena, a partir da organização da educação escolar de forma a constituir-se em instrumento para a compreensão da realidade em suas múltiplas determinações, produzindo o desenvolvimento do indivíduo. Conforme a Psicologia Histórico-Cultural, a educação propicia o desenvolvimento, e não apenas interfere em um desenvolvimento que aconteceria de forma natural, maturacional.

Os conteúdos das várias ciências transmitidos pela escola possibilitam a compreensão do mundo, mas, para que o indivíduo se situe no contexto desse mundo é também necessário compreender como a ação humana o tem transformado e continuará transformando.

Nesse sentido, Sforni (2004, p. 95) afirma:

[...] o desenvolvimento psíquico da criança não é necessariamente desencadeado quando ela é formalmente ensinada ou fica estanque quando não é ensinada por um indivíduo particular, mas quando passa a participar de uma atividade coletiva que the traz novas necessidades e exige dela novos modos de ação. É a sua inserção nessa atividade que abre a possibilidade de ocorrer um ensino realmente significativo.

A escola atual não tem conseguido garantir esse desenvolvimento, entre outras causas, pelo aligeiramento dos conteúdos e pelo fato de ter assumido cada vez mais tarefas periféricas, desviando-se da transmissão dos conteúdos e não possibilitando ao aluno apropriar-se daquilo que lhe é realmente necessário:
O pleno desenvolvimento do indivíduo pressupõe uma apropriação de formas de elevação que se coloquem acima da vida cotidiana. Pressupõe, ainda, que a realidade seja desvelada em suas múltiplas relações e determinações, para além do que é dado imediatamente ao conhecimento, sendo compreendida como realidade social, constituída historicamente pelos homens e não como algo natural. É preciso que se compreendam as relações instituídas e instituintes da organização social e, para tal, é fundamental que a educação possibilite a superação da cotidianidade e conduza à elevação do indivíduo (Leal, 2010, p. 136-137).

Quanto à importância do conhecimento, Vigotski (2000) enfatiza que é por meio do conhecimento adquirido no mundo objetivo que se constrói o mundo subjetivo, e que é com a internalização de conceitos e valores adquiridos por meio da educação que os homens se constituem como seres humanos, estruturando sua consciência e aprendendo a viver em sociedade. Na idade escolar a criança está vinculada aos estudos e é neste período que ela começa a desenvolver as interpretações teóricas e abstratas da realidade.

Segundo Davidov (1988), o período da educação escolar é um momento de mudança essencial na vida da criança, principalmente na forma de organização de sua vida, com as novas obrigações que ela passa a ter como escolar. Os estudos exigem dela certas habilidades que até então não Ihe eram cobradas. Exemplo disto é a disciplina diante de uma série de normas que todos devem seguir, uma submissão que exige da criança o controle de seus comportamentos e em que sua relação com os adultos da escola difere daquela que ela mantém com os pais.

Para Vigotski (1983/2006), com o processo de escolarização forma-se na criança a capacidade de significar os objetos e a si mesma: ela consegue nomear seus sentimentos e identificar os significados de suas experiências. Por meio da educação formal, de acordo com o autor, surgem habilidades psíquicas que lhe permitem orientar conscientemente suas vivências e com isto tem-se um salto qualitativo em sua personalidade.

O ensino escolar deve estimular o aluno na atividade de estudo para que este consiga apropriar-se dos conhecimentos científicos, uma vez que o papel do ensino é direcionar a criança para o desenvolvimento das funções humanas mais elaboradas, para que assim desenvolva seu psiquismo, garanta sua constituição como homem e partícipe do coletivo (Facci, 2004).

\section{2 - Material e Método}

Para a concretização deste estudo, realizamos pesquisas em bancos de dados e indexadores nacionais e internacionais, como o Portal da Capes, o PsycINFO, o LILACS, o Index-Psi (BVS-PSI) e outros, em busca de artigos sobre queixa/fracasso escolar relacionados à dificuldade de aprendizagem, com o objetivo de verificar as concepções de queixa/fracasso escolar e as perspectivas teóricas que funda- 
mentam esta temática presentes nos artigos. Para a busca, foram utilizadas as palavras-chave queixa escolar, fracasso escolar, problemas de aprendizagem, dificuldades de aprendizagem, distúrbios de aprendizagem, dificuldade na leitura e escrita, dificuldade na alfabetização, desempenho escolar.

Foram encontrados 77 artigos, publicados entre 1996 e 2009, dos quais quarenta e seis se concentram nos anos de 2005 a 2007. As informações foram trabalhadas mediante a análise de conteúdo, que, conforme Chizzotti (2005) é um método de tratamento e análise das informações, das formas como os autores configuram o social. O objetivo deste tipo de análise é "[...] compreender criticamente o sentido das comunicações, seu conteúdo manifesto ou latente, as significações explícitas ou ocultas" (p.98).

Ressaltamos que na análise de conteúdo empregou-se, entre as técnicas possíveis, a análise categorial. Neste caso, buscamos discutir as perspectivas teóricas e as concepções de queixa/fracasso escolar verificadas nos artigos pesquisados.

Para facilitar e posibilitar uma melhor visualização, as categorias foram agrupadas em tabelas e posteriormente discutidas, no intuito de compreendê-las e analisá-las para apreender as determinações constitutivas das relações entre as partes e a totalidade. Para tanto, fundamentamo-nos no referencial teórico da Psicologia Histórico-Cultural, que compreende o homem como ser social, histórico e cultural dotado de um psiquismo constituído nas relações estabelecidas com a realidade social. A Psicologia Histórico-Cultural apresenta como base metodológica e princípios epistemológicos o Materialismo Histórico-Dialético, defendido por Marx (1818-1883). Como afirma Duarte (1996, p.105), “(...) existe na postura dessa corrente da psicologia, a nítida influência da concepção de Marx sobre o vir-a-ser histórico da vida em sociedade", haja vista que a história é tomada como um processo de superação da naturalização das relações sociais alienadas.

\section{3 - Resultados e discussão}

Procederemos, nesta seção, à análise das categorias relativas às concepções de queixa/fracasso escolar e às perspectivas teóricas verificadas nos artigos pesquisados.

\section{1- Concepções de queixa/fracasso escolar relacionadas aos problemas de aprendizagem}

A partir da leitura dos textos selecionados nos indexadores buscamos identificar as concepções presentes sobre a queixa/fracasso escolar, classificando-as em quatro categorias: 1) Queixa/fracasso escolar centrado no indivíduo (problemas de aprendizagem relacionados a fatores de ordem individual - aluno, professor e/ou família); 2) Queixa/ fracasso escolar como questão institucional (problemas de aprendizagem relacionados a questões de ordem institucional); 3) Queixa/fracasso escolar e sua relação com a formação profissional (a queixa/fracasso escolar a partir da formação profissional); 4) Queixa/fracasso escolar não centrado no indivíduo (a queixa/fracasso escolar compreendida a partir de determinantes sociais, econômicos, políticos, etc.).

Como podemos observar na tabela 1, a categoria prevalecente nos artigos analisados foi queixa/fracasso escolar centrada no indivíduo, com $67 \%$ das respostas, o que indica que a maioria das produções científicas analisadas neste estudo parte do princípio de que os problemas de escolarização estão relacionados ao aluno, à família ou ao professor. Embora, como apontam Machado e Souza (1997), desde a década de 1980 existam pesquisas que questionam a concepção de que o aluno e a sua família são os únicos responsáveis pelos problemas de aprendizagem e comportamento na escola, chamando a atenção para aspectos como a má qualidade do ensino e a presença de estereótipos e preconceitos em relação à criança pobre, consideramos que ainda é expressivo o número de estudos que se mantêm dentro desta perspectiva individualista e naturalizante. Eidt e Tuleski (2007), em seu estudo, também apontam que grande parte da produção científica atual que trata dos problemas de escolarização centra sua análise unicamente nas características individuais, tomadas como naturalmente patológicas. Bray (2009) afirma que essa forma de compreender os problemas de escolarização desconsidera as condições sociais e econômicas de uma determinada organização social e as complexas relações que a envolvem.

Assim, os problemas de escolarização estão sendo compreendidos de forma descontextualizada, e, como expõe Patto (1992), faz-se recair sobre os indivíduos um

Tabela 1. Concepções de queixa/fracasso escolar

\begin{tabular}{l|l|l}
\hline CATEGORIAS & F & $\%$ \\
\hline Queixa/fracasso escolar centrado no indivíduo & 52 & 67 \\
\hline Queixa/fracasso escolar como uma questão institucional & 7 & 9 \\
\hline Queixa/fracasso escolar relacionada à formação profissional & 4 & 5 \\
\hline Queixa/fracasso escolar não centrada no indivíduo & 15 & 19 \\
\hline TOTAL & 78 & 100 \\
\hline
\end{tabular}

Nota: As porcentagens foram calculadas a partir do total em que aparecem as categorias e não a partir do número de artigos encontrados. 
problema que é de cunho social, analisando-se os fatos em uma perspectiva a-histórica, sem considerar as relações de produção capitalistas e o poder da ideologia neoliberal. Nesta perspectiva, é como se o aluno, a família e o professor não pertencessem a uma sociedade, como se fossem produto deles mesmos.

Foi possível perceber que nos artigos científicos analisados há uma concepção de que, se alguns fatores forem modificados, será possível superar a queixa/fracasso escolar, embora apresentem esses fatores de forma isolada: em alguns se sugere a mudança das relações interpessoais, em outros, a necessidade de melhoria das relações familiares, ou ainda a necessidade de melhorar o autoconceito do aluno, o que mostra que não há uma visão de conjunto, uma análise mais contextualizada do problema e de seus condicionantes.

Em nosso entendimento, estes artigos apresentam uma perspectiva reducionista e naturalizada do problema, pois não consideram a complexidade social em sua totalidade nem analisam a conjuntura socioeconômico-política, pressupondo que, se forem promovidas condições para superar um determinado aspecto (por exemplo, desenvolver habilidades sociais nos alunos), todos os outros aspectos envolvidos no processo educacional estarão resolvidos, alcançando-se o sucesso na aprendizagem. É como se essa sociedade de classes, desigual e regida por valores neoliberais, estivesse alheia às questões educacionais e não participasse na sua constituição.

A concepção da queixa/fracasso escolar não centrada no indivíduo, com um percentual de 19\% das respostas, percentual que, apesar de se baixo, revela a existência de estudos em uma perspectiva que ultrapassa as questões individuais, considerando também fatores de ordem social, econômica e política. Bock (2000) defende esta perspectiva, afirmando que antes de analisar os problemas no processo ensino-aprendizagem como de ordem individual, seguindo o raciocínio da concepção neoliberal, deve-se buscar ir além da aparência. Isto não significa desconsiderar as questões biológicas e os aspectos individuais de cada ser humano, mas compreender o ser humano em sua totalidade, como um ser individual e orgânico que faz parte da história e da sociedade. Afirma Vygotski (1983/2000, p. 90):

Sobre a conduta humana cabe dizer, em geral, que sua peculiaridade, em primeiro lugar, deve-se a que o homem intervém ativamente em suas relações com o meio e que através do meio ele mesmo modifica seu próprio comportamento, subordinando-o a seu poder.

Desta maneira, o comportamento do aluno passa a ser compreendido como síntese de múltiplas determinações. Seu fracasso escolar não se explica somente como fruto de incapacidades orgânicas ou psíquicas, mas de uma multiplicidade de fatores que tem por base as relações estabelecidas na sociedade capitalista.

Constatamos que $9 \%$ dos estudos concebem a queixa/fracasso escolar como uma questão institucional, partindo do princípio de que esta decorre de fatores institucionais, como a falta ou insuficiência de infraestrutura nas escolas para estas desenvolverem um ensino de qualidade.

Há também pesquisas que relacionam os problemas de escolarização à formação profissional (5\% das respostas). Estes estudos explicam a queixa/fracasso escolar como decorrente principalmente da formação deficiente do professor e do psicólogo para exercer sua função. É importante destacar a necessidade de formação profissional de qualidade, mas a formação, por si só, também não explica todas as mazelas da escola, embora se tenha observado que o professor tem tido uma formação que não lhe possibilita o exercício de uma prática social transformadora. Assim o professor acaba sem parâmetros e sem a adequada fundamentação para cumprir sua função de mediação junto ao aluno para que este adquira os conhecimentos historicamente sistematizados, que são fundamentais para o seu desenvolvimento e sua efetiva participação na sociedade (Facci, 2007).

\section{2- Perspectivas teóricas presentes nos artigos analisados}

Para proceder à análise das perspectivas teóricas apresentadas nos artigos pesquisados faz-se necessário esclarecer que nos valemos do conceito de Meira (2003) sobre abordagens críticas. Essa autora compreende o conceito de crítica a partir dos fundamentos teórico-filosóficos desenvolvidos por Marx, segundo os quais “(...) uma concepção ou teoria é crítica à medida que transforma o imediato em mediato; nega as aparências ideológicas; apreende a totalidade do concreto em suas múltiplas determinações e compreende a sociedade como um movimento de vir-a-ser" (Meira, 2003, p.17, grifos da autora).

Neste sentido, uma prática só pode ser crítica a partir do momento em que compreenda a queixa/fracasso escolar mediante uma análise profunda do fenômeno educacional, que considere as múltiplas determinações envolvidas em um contexto histórico concreto.

Como podemos observar na tabela 2, a maioria dos artigos analisados (65\%) apresenta uma abordagem não crítica. Este resultado nos permite inferir que há um número expressivo de pesquisadores no meio acadêmico desenvol-

Tabela 2. Perspectivas teóricas presente nos artigos.

\begin{tabular}{l|l|l}
\hline CATEGORIAS & $\mathrm{F}$ & $\%$ \\
\hline Textos com abordagem não crítica & 50 & 65 \\
\hline Textos com abordagem crítica & 24 & 31,1 \\
\hline $\begin{array}{l}\text { Textos com abordagem crítica/ não } \\
\text { crítica (ecletismo) }\end{array}$ & 3 & 3,9 \\
\hline Total & $\mathbf{7 7}$ & 100 \\
\hline
\end{tabular}

Nota: As porcentagens foram calculadas a partir do total em que aparecem as categorias e não a partir do número de artigos encontrados. 
vendo estudos que compreendem a queixa/fracasso escolar em uma perspectiva individualizante.

Neste sentido, a queixa/fracasso escolar é atribuída ao aluno por se acreditar que se localizam somente nele as características necessárias para o seu bom desempenho escolar. Essas concepções ideológicas acerca da realidade escolar encontram respaldo em diversas áreas das ciências, principalmente na Psicologia e na Medicina, fortalecendo-as e garantindo-Ihes credibilidade. Informa Yazlle, (1997, p. 15):

A bibliografia disponível nos indica que a Psicologia, enquanto instrumento aplicado às práticas educacionais, se origina justamente no final do século XIX, com o empenho dos educadores e cientistas do comportamento em classificarem crianças com dificuldades escolares e proporem às mesmas métodos especiais de educação, a fim de ajustá-las aos padrões de normalidade definidos pela sociedade.

Neste sentido, Souza (2000) afirma que desde sua origem como ciência, na metade do século XIX, em plena sociedade capitalista, a Psicologia vem procurando atender aos interesses da classe burguesa, com uma concepção tecnicista do homem e do mundo. Isso está ligado principalmente ao fato de a Psicologia, ao se constituir como ciência, pautar-se nos moldes positivistas. Como consequência, aguçou-se a visão biologizante e reducionista com relação aos fenômenos humanos, intensificando a prática de avaliações padronizadas e classificações que disfarçam os aspectos ideológicos e as relações de poder presentes em uma sociedade de classes.

Entre os artigos analisados encontramos $31,1 \%$ que apresentam uma abordagem crítica, percentual que, embora seja baixo, demonstra um avanço no campo da Psicologia e da Educação, se considerarmos que até a década de 1980 os problemas de escolarização eram compreendidos apenas pelo viés de culpabilização do indivíduo, ou seja, do ponto de vista do aluno ou do seu meio familiar.

A partir dos artigos analisados verificamos que prevalece nos estudos uma abordagem não crítica, com o predomínio das produções em que a queixa/fracasso é compreendida pela ótica do indivíduo, sem reflexões que contemplem a historicidade do processo, o que evidencia uma forma de negar as contingências sociais e econômicas que envolvem os problemas educacionais.

Segundo Arroyo (2000), pensar o fracasso escolar em um contexto mais amplo e social significa focalizar a escola como instituição e como materialização de uma lógica seletiva e excludente. Ao considerarmos o que expôs o autor, salientamos que, enquanto não pensarmos nessa direção e não transformarmos a estrutura rígida e seletiva de nosso sistema escolar, não estaremos enfrentando o problema do fracasso escolar. Por isso é necessário buscar formas de entender as dificuldades escolares que não produzam rotulações, mas formas que permitam

(...) analisar o processo de escolarização e não os problemas de aprendizagem deslocando o eixo da análise do indivíduo para a escola e o conjunto de relações institucionais, históricas, psicológicas, pedagógicas que se fazem presentes e constituem o dia a dia escolar (Souza, 2000, p.123, grifos da autora).

Encontramos também artigos que podem ser classificamos como ecléticos (3,9\%), pois em alguns momentos apresentam elementos de criticidade e em outros demonstram argumentações reducionistas, que se caracterizam como não críticas. Como indicam Angelucci, Kalmus, Paparelli e Patto (2004), pode ser evidenciado um "discurso fraturado". Com isto compreendemos que, nos artigos analisados sobre a queixa escolar, concepções críticas e não críticas se mesclam, passando-se a conjecturar num mesmo texto as explicações sobre o fenômeno em questão, numa apropriação superficial da teoria, com a falta de consistência teórica. Desta maneira, os autores destes artigos lançam mão de uma teoria crítica ao longo de sua composição, mas ao procederem às analises do objeto de pesquisa resgatam explicações reducionistas, deixando-se guiar pelas ideologias massivamente disponíveis, que em geral centram no indivíduo o cerne do fracasso escolar.

Neste aspecto, destacamos a importância e a necessidade de estarmos atentos às contradições engendradas nos estudos produzidos, as quais muitas vezes mascaram a realidade e apresentam um caráter de dubiedade em relação a ela, não a problematizam e assim podem confundir o leitor ou, ainda, convencê-lo por meio de falácias.

\section{4 - Conclusões}

O presente estudo nos possibilitou compreender como a queixa/fracasso escolar, no que tange às dificuldades de aprendizagem, vem sendo divulgada em periódicos científicos de grande circulação no Brasil. Pela leitura e análise dos 77 artigos encontrados identificamos quatro grandes eixos que embasaram as concepções que fundamentam as reflexões neles presentes sobre a queixa/fracasso escolar: 1) queixa/fracasso escolar centrada no indivíduo; 2) queixa/fracasso escolar como questão institucional; 3) queixa/ fracasso escolar relacionada à formação profissional; e 4) queixa/fracasso escolar não centrada no indivíduo.

A partir das informações encontradas, verificamos uma grande ênfase nas concepções individualizantes em relação à queixa/fracasso escolar, evidenciada pela apologia exacerbada ao potencial intelectual considerado inato, próprio de cada indivíduo. Desta forma, o processo de escolarização vem sendo encarado como responsabilidade individual - do aluno, do professor ou da família. Esta individualização desconsidera a totalidade que envolve o processo de escolarização e, ao culpabilizar o indivíduo, retira a responsabilidade da sociedade baseada no modo de produção capitalista, sistema que implica divisão de classes, relações sociais antagônicas, domínio de uma classe sobre as outras, a necessidade de manter um equilíbrio entre os homens - mesmo que aparente, uma vez que não há equi- 
líbrio possível entre pessoas de classes antagônicas - e outras consequências, enfraquecendo nos trabalhadores a capacidade de lutar por seus direitos. Neste sentido, o tipo de organização escolar existente responde à necessidade da sociedade de se perpetuar, mediante a formação de indivíduos adaptados e submissos, que reconheçam em si mesmos a possibilidade de sucesso e responsabilizem-se por seu fracasso, isentando o meio social.

As concepções que integram os artigos consideram, em sua maioria (as não críticas), apenas uma parte da problemática. Isso leva à necessidade de buscarmos condições para superar esta situação, o que envolve inúmeros fatores, entre eles a formação de psicólogos numa perspectiva crítica e de comprometimento com o processo de humanização, para assim se superar o viés clínico no trato da queixa/fracasso escolar e deixar-se de lidar com esse fenômeno como se fosse um problema individual. Por outro lado, embora não tenha sido a tônica dos artigos, não podemos negar a existência de alguns estudos que ampliam a compreensão da queixa/fracasso escolar. Neste sentido, concordamos com a concepção que considera a totalidade dos fatos e as suas contradições, questionando a sociedade e o modo de produção e entendendo-os como fatores determinantes na educação e no processo de desenvolvimento e aprendizagem do homem. Precisamos repensar as reformas educacionais trazendo discussões mais condizentes e críticas, que não compactuem com a reprodução desse tipo de sociedade e escola que temos.

Os artigos, em sua maioria, não consideram as dimensões sociais e históricas que permeiam todas as relações humanas e constituem a queixa/fracasso escolar. Quando a reflexão ocorre, é possível desvendar algumas circunstâncias a respeito de como se constrói o estereótipo de quem aprende ou quem não aprende, pois, em geral, os problemas de escolarização se fundamentam no que é aparente, desconsiderando as condições que, quando reveladas, promovem a possibilidade de alterar as concepções e as ações no ambiente escolar.

Como pudemos ver, não são estudos com uma abordagem crítica que prevalecem, mas aqueles de abordagem não crítica, o que torna ainda mais significativa a necessidade de mais publicações que busquem a compreensão das diversas influências capazes de afetar tanto a aprendizagem do aluno quanto seu comportamento na escola e os sentidos das mazelas produzidas e identificadas no contexto escolar, as quais são indissociáveis da sociedade capitalista. Produções nessa linha podem conduzir às transformações necessárias para a concretização do sucesso escolar e das possibilidades de participação social do indivíduo.

Reforçamos que a nossa sociedade adota uma postura de procurar culpados para fenômenos de grande complexidade, em uma perspectiva de individualização e naturalização dos fenômenos, sem contemplar as condições materiais dos homens e o lugar que eles ocupam nas relações sociais. Assim, tendemos a pensar que todos somos iguais e que a pobreza/riqueza ou sucesso/fracasso são construções de cada um de nós e não têm relação com os aspectos eco- nômicos que ditam e direcionam a vida dos homens, pois a todo o momento nos é imposta uma ideologia que oculta as diferenças com um discurso que prega a igualdade.

Nessa direção, a Psicologia Histórico-Cultural pressupõe a análise crítica, que permite a desnaturalização das explicações sobre a não aprendizagem dos alunos, envolvendo o exercício "(...) de pôr os fatos em relação entre si e com as condições objetivas da realidade" (Silva, Facci, Eidt, Tuleski, \& Barroco, 2008, p.415). As autoras alertam sobre a importância de desconfiar do que se mostra naturalmente constituído para além das aparências do insucesso escolar. Neste sentido, cotidianamente observamos o estranho se tornar natural pela frequência com que ocorre e por, forçosamente, em estudos e avaliações, buscarmos encontrar o que já era naturalmente esperado, principalmente quando tratamos dos alunos considerados problemáticos e deficientes (Rossato, 2010).

Nesse contexto, as produções científicas devem contribuir para desnaturalizar a crença de que as crianças e adolescentes com dificuldades de aprendizagem são naturalmente fracassadas. É preciso desvelar o fenômeno educacional destes alunos, estranhar, questionar por que tantos estudos ainda centram neles o insucesso escolar. Não podemos discutir a questão da queixa/fracasso escolar sem discutir e considerar o contexto historicamente constituído da sociedade, da divisão de classes, da família e das escolas.

\section{Referências}

Anuário Brasileiro da Educação Básica 2013 (2013). Todos pela Educação. Ed. Moderna. Recuperado: 07 maio 2013. Disponível: http://www.moderna.com.br /lumis/portal/file/fileDownload.jsp

Angelucci, C. B., Kalmus, J., Paparelli, R., \& Patto, M. H. S. (2004). O estado da arte da pesquisa sobre o fracasso escolar (1991-2002): um estudo introdutório. Educação e Pesquisa, 30 (1), São Paulo, $51-72$.

Arroyo, M. G. (2000). Fracasso/Sucesso: um pesadelo que perturba nossos sonhos. Em aberto, 17 (71), 33-40.

Bock, A. M. B. (2000). As influências do Barão de Munchausen na Psicologia da Educação. Em E. R. Tanamachi, M. L. Rocha, \& M. P. R. Souza (Orgs.), Psicologia e Educação: desafios teóricospráticos (pp.11-33). São Paulo: Casa do Psicólogo.

Brasil- Governo Federal (2013). Indicadores de Desenvolvimento Brasileiro. Assessoria Econômica do Ministério do Planejamento, Orçamento e Gestão. Recuperado: 27 jun. 2013. Disponível: http://www.planejamento.gov.br/secretaria s/upload/Arquivos/ publicacao/indicadores_de_desenvolvimento.pdf .

Bray, C. T. (2009). Queixas escolares na perspectiva de educadores das redes pública e privada: contribuição da Psicologia HistóricoCultural. Dissertação de Mestrado, Universidade Estadual de Maringá, Maringá-PR. 
Davidov, V. (1988). La ensenãnza escolar y el desarrollo psiquico: investigación teórica y experimental. Moscu: Editorial Progresso.

Duarte, N. (1996). A escola de Vigotski e a educação escolar: hipóteses para uma leitura pedagógica da Psicologia HistóricoCultural. Em N. Duarte, Educação Escolar, teoria do cotidiano e a escola de Vigotski (pp.76-106). Coleção Polêmicas do nosso tempo. Campinas: Autores Associados.

Chizzotti, A. (2005). Pesquisa em Ciências Humanas e Sociais (7a ed.) São Paulo: Cortez.

Eidt, N. M. e Tuleski, S. C. (2007). Repensando os distúrbios de aprendizagem a partir da Psicologia Histórico-Cultural. Psicologia em Estudo, 12 (3), 531-540.

Facci, M. G. D. (2007). "Professora, é verdade que ler e escrever é uma coisa tão fácil?"- Reflexões em torno do processo ensinoaprendizagem na perspectiva Vigotskiana. Em M. E. M. Meira, \&. M. G. D. Facci (Orgs.), Psicologia Histórico-Cultural: Contribuições para o encontro entre a subjetividade e a educação (pp.135-156). São Paulo: Casa do Psicólogo.

Facci, M. G. D. (2004). Valorização ou esvaziamento do trabalho do professor? Campinas, SP: Autores Associados.

Leal, Z. F. R. G. (2010). Educação escolar e constituição da consciência: um estudo com adolescentes a partir da Psicologia Histórico-Cultural. Tese de Doutorado, Universidade de São Paulo, São Paulo-SP.

Machado, A. M. (1997). Avaliação e fracasso: a produção coletiva da queixa escolar. Em J. G. Aquino (Org.), Erro e Fracasso na escola: alternativas teóricas (pp.73-90). São Paulo: Sumus.

Machado, A. M., \& Souza, M. P. R. (1997). As crianças excluídas da Escola: Um alerta para a Psicologia Escolar. Em A. M. Machado, \& M. P. R. Souza (Orgs.), Psicologia Escolar: em busca de novos rumos (pp.35-49). São Paulo: Casa do Psicólogo.

MEC- Ministério da Educação. (2013). Educação Básica: Censo Escolar revela aumento de matrículas em tempo integral. 2013. Recuperado: 06 de maio de 2014. Disponível: http://portal.mec. gov.br/index.php?option=com_content\&view=articl e\&id=20264.

Meira, M. E. M. (2003). Construindo para uma concepção crítica de psicologia escolar: contribuições da Pedagogia HistóricoCrítica e da Psicologia Histórico-Cultural. Em M. E. M. Meira, \& M. A. M. Antunes (Orgs.), Psicologia escolar: teorias críticas (pp.1378). São Paulo: Casa do Psicólogo.
Patto, M. H. S. (1992). A família pobre e a escola pública: anotações sobre um desencontro. Psicologia USP, 3 (1-2), 107-121.

Patto, M. H. S. (1990). A produção do fracasso escolar: histórias de submissão e rebeldia. São Paulo: T.A. Queiroz.

Rossato, S. P. M. (2010). Queixa escolar e educação especial: intelectualidades invisíveis. Dissertação de Mestrado, Universidade Estadual de Maringá, Maringá-Pr.

Silva, G. L. R., Facci, M. G. D., Eidt, N. M., Tuleski, S. C., \& Barroco, S. M. S. (2008). Dificuldades de aprendizagem ou dificuldades de escolarização? Um debate a partir do referencial da psicologia histórico-cultural. Em M. A. Almeida, E. G. Mendes, \& M. C. P. I. Hayashi (Orgs.), Temas em Educação Especial: múltiplos olhares (pp. 413-421). Araraquara, SP: Junqueira \& Marin.

Sforni, M. S. F. (2004). Aprendizagem conceitual e organização do ensino: contribuições da teoria da atividade. Araraquara: JM Editora.

Souza, B. P. (2007). Funcionamentos escolares e a produção de fracasso escolar e sofrimento. Em B. P. Souza (Org.), Orientação à queixa escolar (pp. 241-278). São Paulo: Casa do Psicólogo.

Souza, M. P. R. (2000). A queixa escolar na formação de Psicólogos: Desafios e perspectivas. Em E. Tanamachi, M. Rocha, \& M. Proença (ORGS.), Psicologia e Educação: desafios teóricopráticos (pp.105-142). São Paulo: Casa do Psicólogo.

UNESCO (Organização das Nações Unidas para a Educação, a Ciência e a Cultura). (2010). Relatório de Monitoramento Global de Educação para Todos 2010: Relatório Conciso. Brasília: Ed. UNESCO.

Vigotski, L. S. (2006). Obras Escogidas (tomo IV). $2^{\mathrm{a}}$ edição. Madrid: A. Machado Libros S.A. (Trabalho original publicado em 1983).

Vigotski, L. S. (2000). A Construção do Pensamento e da Linguagem. São Paulo: Martins Fontes.

Vygotski, L. S. (2000). Obras Escogidas (tomo III). Madrid: Visor Distribuciones. (Trabalho original publicado em 1983).

Yazlle, E.G. (1997). Atuação do Psicólogo escolar: Alguns dados históricos. Em Cunha, B.B. Psicologia na escola: Um pouco de história e algumas histórias (pp.11-38). São Paulo: Arte e Ciência. 


\section{Sobre as autoras}

Nilza Sanches Tessaro Leonardo (nilza_sanches@yahoo.com)

Doutora em Psicologia, PUC/SP; Professora do Departamento de Psicologia da Universidade Estadual de Maringá-PR

Záira Fátima de Rezende Gonzalez Leal (zairaleal@yahoo.com)

Doutora em Psicologia Escolar e do Desenvolvimento, USP/SP; Professora do Departamento de Psicologia da Universidade Estadual de Maringá-PR

Solange Pereira Marques Rossato (solmarques@hotmail.com)

Doutoranda do Programa de Pós-graduação em Psicologia da UNESP/Assis- SP

Trabalho decorrido do Projeto de Pesquisa intitulado: Fracasso/queixa escolar e a Psicologia Histórico-cultural: um estudo exploratório, realizado na Universidade Estadual de Maringá. 